\title{
X-ray Diffraction Analysis of Rust Layer on a Weathering Steel Bridge with Surface Treatment Using Synchrotron Radiation
}

\author{
Masato Yamashita ${ }^{1}$, Shuichi Hara ${ }^{2}$, Takayuki Kamimura ${ }^{3}$, Hideaki Miyuki ${ }^{3}$ and Masugu Sato ${ }^{4}$ \\ ${ }^{1}$ Division of Mechanical Engineering, Graduate School of Engineering, University of Hyogo, Himeji 671-2280, Japan \\ ${ }^{2}$ Investigation \& Research Div., Sumitomo Metal Technology Inc., Amagasaki 660-0891, Japan \\ ${ }^{3}$ Corporate Research and Development Laboratories, Sumitomo Metal Industries, Ltd., Amagasaki 660-0891, Japan \\ ${ }^{4}$ Industrial Application Div., Japan Synchrotron Radiation Research Institute, Sayo, Hyogo 679-5198, Japan
}

We have examined the structure of rust layer formed on a weathering steel bridge, to which the surface treatment, employing the effect of $\mathrm{Cr}_{2}\left(\mathrm{SO}_{4}\right)_{3}$ sophisticatedly designed to form the protective goethite $(\alpha-\mathrm{FeOOH})$ rust layer which contains a certain amount of $\mathrm{Cr}$, Cr-goethite, was applied in 1996, using X-ray diffraction at SPring-8 synchrotron radiation facility. It was shown that the formation of $\alpha$-FeOOH was promoted and/or crystal growth of $\gamma-\mathrm{FeOOH}$ was suppressed by the surface treatment. The increase in the protective ability index (PAI) of the rust layer indicates that the protective goethite was predominantly formed under the effect of the surface treatment. In conclusion, it can be said that the surface treatment worked well to promote the formation of the protective goethite rust layer on the weathering steel bridge during the 10year exposure. [doi:10.2320/matertrans.48.579]

(Received October 20, 2006; Accepted December 25, 2006; Published February 25, 2007)

Keywords: atmospheric corrosion, rust layer, weathering steel, synchrotron radiation, X-ray diffraction, protective ability index (PAI)

\section{Introduction}

Weathering and deterioration, namely corrosion, of iron and steel have been age-long problems that have faced mankind after the Iron Age. In modern times, highway bridge is an important part of the infrastructure and transportation system that allows a high level of mobility and freight activities. In the near future, the total number of aged bridges in Japan will steeply increase up to more than 20,000. To secure the longevity of steel bridges, therefore, is an important technological subject, which will benefit present society and future generations over the next few centuries.

Weathering steel containing a small amount of $\mathrm{Cr}, \mathrm{P}$ and $\mathrm{Cu}$ spontaneously forms an adherent rust layer which protects the steel from the environment and reduces the corrosion loss for a long period. Thus, the weathering steel has dramatically increased the number of steel bridges being built in the last decades since the weathering steel does not require painting due to the formation of the protective rust layer during in service and large reduction of maintenance cost is expected.

The structure of the protective rust layer of the weathering steel has been studied by various spectroscopic techniques such as X-ray diffraction ${ }^{1-3)}$ and Mössbauer ${ }^{4-6)}$ spectroscopies. It has been revealed that the protective rust layer consists of ultrafine crystals of ferric oxyhydroxides and the protective effect is derived from the dense aggregation of ultrafine goethite which contains a certain amount of $\mathrm{Cr}$, $\mathrm{Cr}$-goethite. The increase in $\mathrm{Cr}$ concentration in the $\mathrm{Cr}$ goethite results in a decrease in the crystal size ${ }^{7)}$ and emphasis on the cation selectivity, ${ }^{8)}$ providing a high protective ability of the protective goethite rust layer against atmospheric corrosives.

Applying the weathering steel as bridge material, it must be recognized that the protective rust layer can form under regular wet-dry cycling in the environment without aggressive corrosives such as chloride ion. In other words, the longevity of weathering steel structures is closely controlled by the environments in which they are located. Moreover, the protective rust can be formed after several-year exposure, thus the initial corrosion increases mass loss of the steel.

In order to avoid the above mentioned problems of the weathering steel, promotion of the protective rust formation has been schemed employing a surface treatment that has been developed for the weathering steel. ${ }^{9,10)}$ The surface treatment was designed to form the protective Cr-goethite nano particles employing the effect of $\mathrm{Cr}_{2}\left(\mathrm{SO}_{4}\right)_{3}$. Detailed concept of the surface treatment was addressed in literature. ${ }^{9,10)}$

In the present study, we examine the structure of rust layer formed during 10 years on a weathering steel bridge to which the surface treatment was first applied in 1996.

\section{Experimental Procedure}

\subsection{Rust samples}

The rust layers examined were formed on a box girder of a weathering steel bridge of a highway located in a mountain area, $80 \mathrm{~km}$ away from the sea of Japan, in Gifu Prefecture, Japan. Little amount of airborne sea-salt particles is expected in the environment as will be argued later. The examined portion did not directly exposed to the rain because it is the middle one of the three girders underneath the slab of the bridge. The surface treatment promoting the protective rust layer formation $^{9,10)}$ was coated at $30 \times 10^{-6}$ m thick to $0.5 \mathrm{~m}$ width of the box girder close to an abutment of the bridge in January 1996. This surface treatment consisted of butyral resin, usual paint pigments, $\mathrm{H}_{3} \mathrm{PO}_{4}$ and $\mathrm{Cr}_{2}\left(\mathrm{SO}_{4}\right)_{3}$, diluted with a solvent, and did not contain protective $\mathrm{Cr}$-goethite, as shown in Table 1.

Rust samples were collected from the vertical member (web), the skyward surface of the lower horizontal flange (flange-skyward) and the earthward surface of the lower horizontal flange (flange-earthward) both of the surface- 
Table 1 Main composition of the surface treatment promoting the protective rust layer formation.

\begin{tabular}{lc}
\hline \multicolumn{1}{c}{ Components } & mass\% \\
\hline Resin(Polyvinyl butyral, etc $)$ & $35-55$ \\
Pigments $\left(\mathrm{Fe}_{2} \mathrm{O}_{3}\right.$, Carbon black, $\mathrm{BaSO}_{4}$, talc, etc) & $10-30$ \\
$\mathrm{Cr}_{2}\left(\mathrm{SO}_{4}\right)_{3}$ & $10-40$ \\
$\mathrm{H}_{3} \mathrm{PO}_{4}$ & $2-10$ \\
\hline
\end{tabular}

treatment and non-treatment (bare) portions in September 2005 approximately 10 years after the successfully application of the surface treatment. Because we collected samples from a bridge in service, collecting amount of the sample allowed was inevitably restricted to very small. Thus, in this experiment, we collected the samples less than a few mg for each portion using a precise razor until the steel surface become visible, and then ground into powder. The powdered rust sample was desiccated for several weeks in advance of the analysis. We also prepared pure $\alpha-\mathrm{FeOOH}$ (goethite), $\beta$ $\mathrm{FeOOH}$ (akaganeite), $\gamma$-FeOOH (lepidocrocite) and $\mathrm{Fe}_{3} \mathrm{O}_{4}$ (magnetite) powder samples by artificial method ${ }^{11)}$ for reference.

\subsection{X-ray diffraction spectroscopy}

The rust samples were characterized by means of X-ray diffraction (XRD) spectroscopy using SPring-8 BL19B2 synchrotron radiation. As was mentioned above, collected amount of samples were restricted to very small, a few $\mathrm{mg}$, thus high brilliant synchrotron radiation X-rays were employed for obtaining higher quality XRD pattern. All the samples were firmly packed in a narrow Lindemann glass capillary (outer diameter $0.3 \mathrm{~mm}$ and glass thickness 0.01 $\mathrm{mm}$ ) and positioned parallel to the X-ray beam with the linesegment shape sized $3.0 \mathrm{~mm}$ horizontal and $0.3 \mathrm{~mm}$ vertical. During the measurement, the capillary was continuously rotated at the rate of approximately $2 \mathrm{~s}^{-1}$. The wave length of the X-ray was adjusted to $0.075 \mathrm{~nm}$ that corresponds to $16.46 \mathrm{keV}$ which avoided higher background signals due to fluorescence and was low enough to obtain satisfactory resolution. The diffraction intensity was recorded to an imaging plate.

\section{Results and Discussion}

\subsection{XRD pattern}

The XRD patterns of the standard samples are shown in Fig. 1. The relative peak intensities of the patterns are well consistent with the Powder Diffraction File ${ }^{12)}$ distributed by the International Centre for Diffraction Data. Figures 2, 3 and 4 indicate the XRD patterns of the rust layer collected at the bare and the surface-treatment coated portions of the web, the flange-skyward and the flange-earthward, respectively. The peak intensity was normalized using the strongest line of $\alpha$ $\mathrm{FeOOH} /(110)$ at $2 \theta=10.25^{\circ}$. Each diffraction peak was assumed as those of the iron oxide and oxyhydroxides shown in Fig. 1. In addition, some pigments consisted in the surface treatment such as $\alpha-\mathrm{Fe}_{2} \mathrm{O}_{3}$, and $\mathrm{Mg}_{3} \mathrm{Si}_{4} \mathrm{O}_{10}(\mathrm{OH})_{2}$ were also observed in the rust layer of the coated portion. The peak intensities of those pigments are higher in the flange-skyward probably because easier accumulation on the outermost

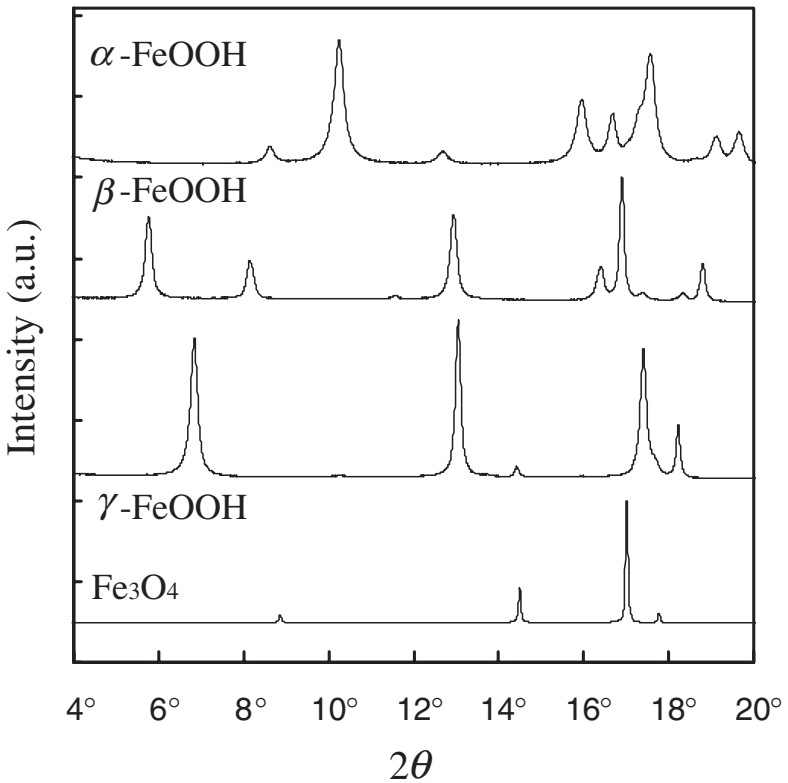

Fig. 1 X-ray diffraction patterns of artificially formed $\alpha$-FeOOH, $\beta$ $\mathrm{FeOOH}, \gamma$-FeOOH and $\mathrm{Fe}_{3} \mathrm{O}_{4}$.

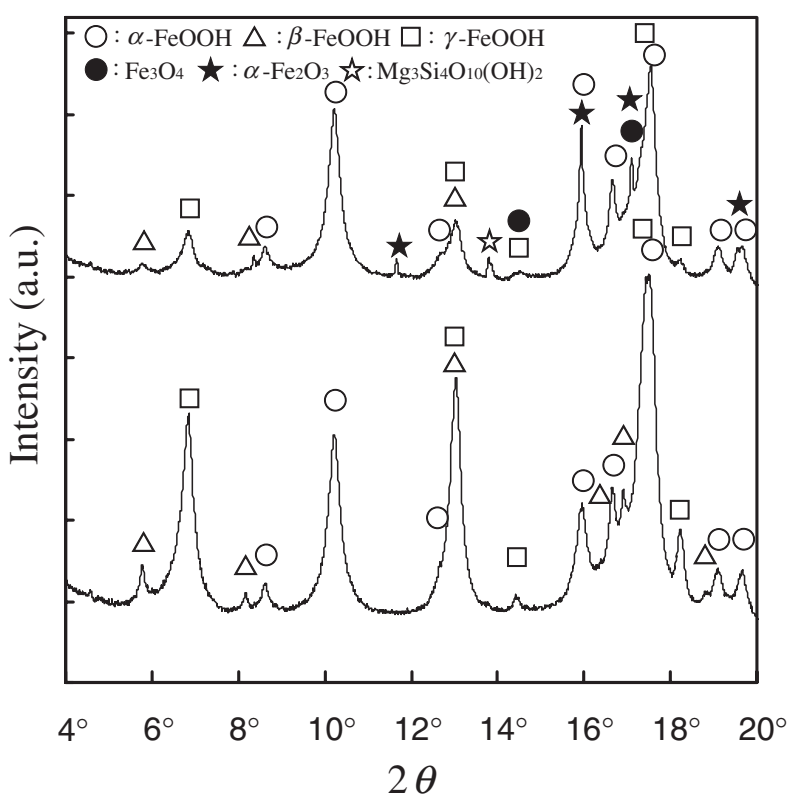

Fig. 2 X-ray diffraction patterns of the rust layer formed on the vertical member (web) of the weathering steel bridge with (upper) and without (lower) the surface treatment.

surface of the upper side of the horizontal member.

By comparing the XRD patterns between the rust layers of the bare and coated portions, it is clear that the peak intensity of $\gamma$-FeOOH is much lower in the coated portion. This implies that the formation of $\alpha-\mathrm{FeOOH}$ was encouraged and/ or crystal growth of $\gamma-\mathrm{FeOOH}$ was suppressed by the surface treatment.

Cornell and Schwertmann ${ }^{13)}$ pointed out that $\mathrm{SO}_{4}{ }^{2-}$ ion has an $\alpha$-FeOOH promoting effect. Tamaura et al. ${ }^{14)}$ showed that with lower concentration of $\mathrm{SO}_{4}{ }^{2-}$ ion air oxidation of $\mathrm{Fe}(\mathrm{OH})_{2}$ suspension results in formation of $\mathrm{Fe}_{3} \mathrm{O}_{4}$, and that $\alpha-\mathrm{FeOOH}$ is preferentially formed at $\mathrm{SO}_{4}{ }^{2-}$ ion concentra- 


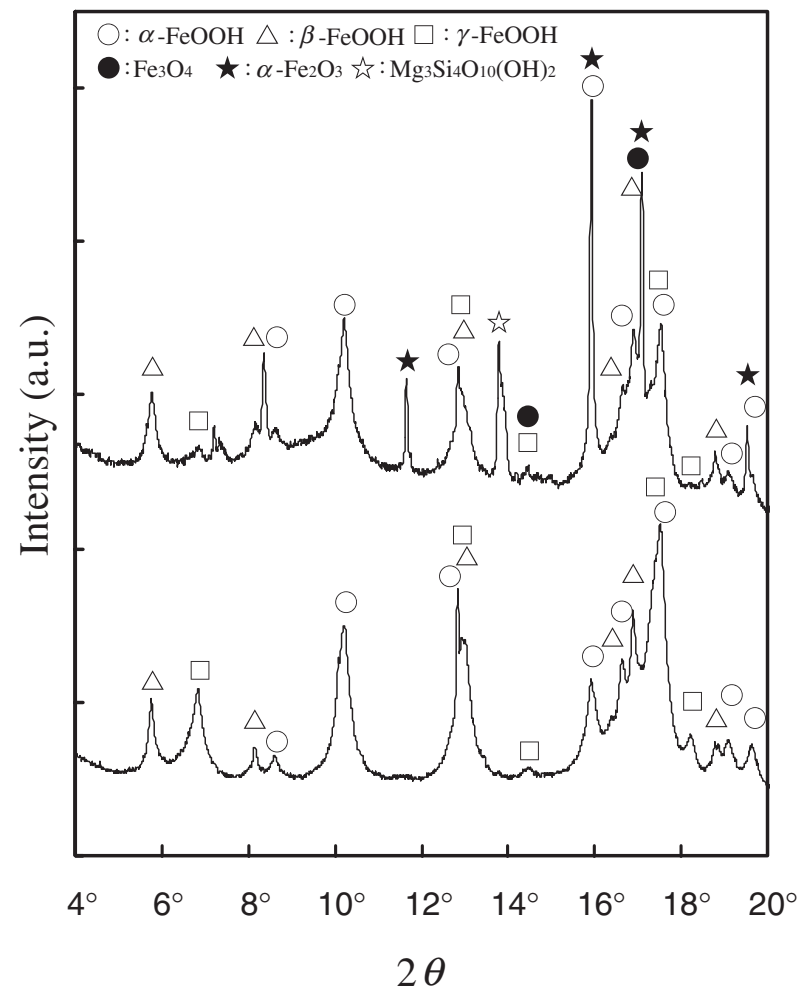

Fig. 3 X-ray diffraction patterns of the rust layer formed on the skyward surface of the lower horizontal flange (flange-skyward) of the weathering steel bridge with (upper) and without (lower) the surface treatment.

tion of $0.1 \mathrm{kmol} / \mathrm{m}^{3}$. Yamashita et al. ${ }^{15)}$ observed rust formation processes using synchrotron radiation X-rays and showed that $\alpha$-FeOOH was preferentially formed under the effect of $\mathrm{SO}_{4}{ }^{2-}$ ion. Moreover, it was pointed out that $\mathrm{Cr}$ become a nucleus for the growth of $\alpha-\mathrm{FeOOH}^{16)}$ because $\mathrm{Cr}$ is less soluble in $\gamma$-FeOOH than in $\alpha$-FeOOH. Therefore, it can be said that $\mathrm{Cr}_{2}\left(\mathrm{SO}_{4}\right)_{3}$ in the surface treatment promoted $\alpha$-FeOOH formation, actually the Cr-goethite formation, and suppressed growth of $\gamma$-FeOOH crystals on the weathering steel bridge.

In addition, existence of $\beta$-FeOOH was also shown in Figs. 2, 3 and 4 . The structure of $\beta$-FeOOH consists of double chains of edge-shared $\mathrm{FeO}_{3}(\mathrm{OH})_{3}$ octahedra running parallel to give a tunnel bounded by double rows of corner shared chains. ${ }^{13)}$ This tunnel in $\beta$-FeOOH can be stabilized by $\mathrm{Cl}^{-}$ion. Therefore, it is pointed out that a certain amount of airborne salt has been present at the bridge site originated probably from deicing salt sprinkled at surrounding areas since the bridge site is $80 \mathrm{~km}$ far away from the Sea of Japan.

The peak intensities due to $\beta$-FeOOH at the coated portions of the web and the flange-earthward were lower than those at the bare ones, indicating that the surface treatment suppressed penetration of $\mathrm{Cl}^{-}$ion through the rust layer. It was pointed out on a basis of the X-ray absorption fine structure of the rust layer formed on weathering steel exposed to an atmosphere for 17 years that $\mathrm{Cr}^{3+}$ in the protective $\mathrm{Cr}$ goethite rust layer is coordinated with $\mathrm{O}^{2-}$ and is located in the double chains of vacant sites in the network of $\mathrm{FeO}_{3}(\mathrm{OH})_{3}$ octahedra as a surface-adsorbed and/or intergranular ion in $\alpha$-FeOOH crystal; ${ }^{17)}$ this $\mathrm{Cr}^{3+}$ site encourages

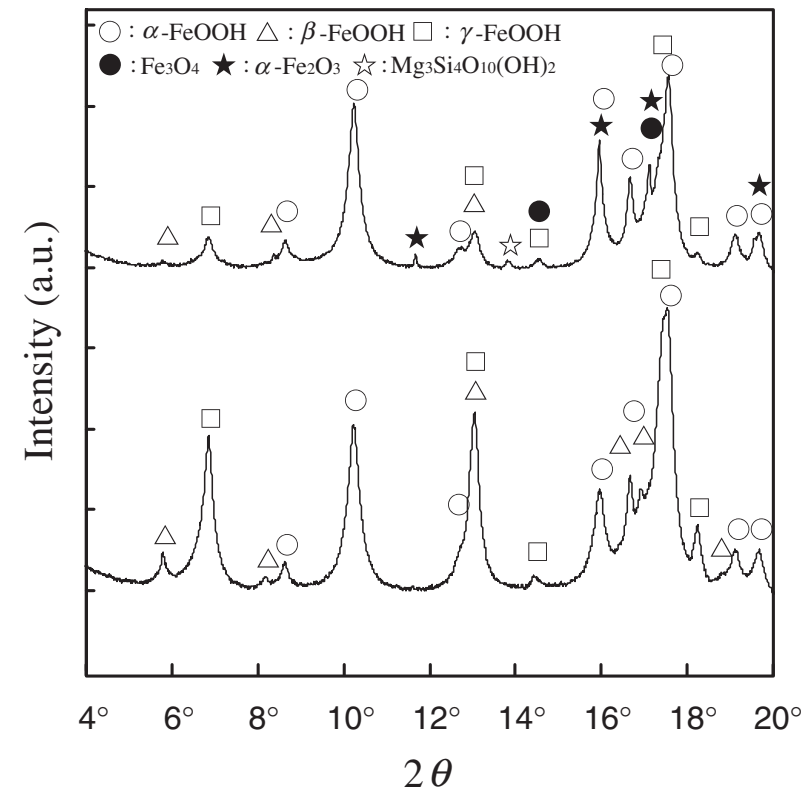

Fig. 4 X-ray diffraction patterns of the rust layer formed on the earthward surface of the lower horizontal flange (flange-earthward) of the weathering steel bridge with (upper) and without (lower) the surface treatment.

cation selectivity of the protective $\mathrm{Cr}$-goethite. The present results indicating that the surface treatment suppressed penetration of $\mathrm{Cl}^{-}$ion, showed that the $\mathrm{Cr}^{3+}$ in the surface treatment promotes the formation of the $\mathrm{Cr}$-goethite and gives the cation selectivity to the rust layer. Then, the cation selectivity suppresses the penetration of $\mathrm{Cl}^{-}$ion coming from atmospheric environment and thus the formation of $\beta$ $\mathrm{FeOOH}$ is suppressed.

Kamimura et al. ${ }^{18)}$ pointed out by Mössbauer spectroscopic study of $\beta$-FeOOH that the particle size decreases by the effect of $\mathrm{SO}_{4}{ }^{2-}$ ion and $\mathrm{Cr}$ incorporation into $\beta$-FeOOH. The obtained low diffraction intensity of $\beta$-FeOOH at the coated portions might be partly due to those effects on $\beta$ $\mathrm{FeOOH}$.

The peak intensities assigned to $\beta$-FeOOH at the coated and non-coated portions of the flange-skyward were relatively high. This is highly likely due to accumulation of salt particles on the outermost surface of the flange-skyward just like the similar behavior of the pigments in the surface treatment.

\subsection{Composition and the protective ability index}

Analysis of the weathering steel bridge rust layer by XRD showed that this method can easily give the protective goethite fraction in the rust layer. It was shown that the fraction of $\alpha-\mathrm{FeOOH}$ is closely related to the corrosion rate of the weathering steel. Yamashita et al. ${ }^{2)}$ has shown strong correlation between corrosion rate and the mass ratio $(\alpha / \gamma)$ of crystalline $\alpha$-FeOOH to $\gamma$-FeOOH formed under the environment without or low chloride concentration. When the $\alpha / \gamma$ is more than a certain value, the corrosion rate of the weathering steel was suppressed less than $0.01 \mathrm{mmy}^{-1}$ which is the acceptable corrosion rate of the weathering steel coated by the protective rust layer. Moreover, Yamashita et al. ${ }^{19,20)}$ Shiotani et $a l .{ }^{21)}$ and Kamimura et al. ${ }^{11)}$ have shown the 


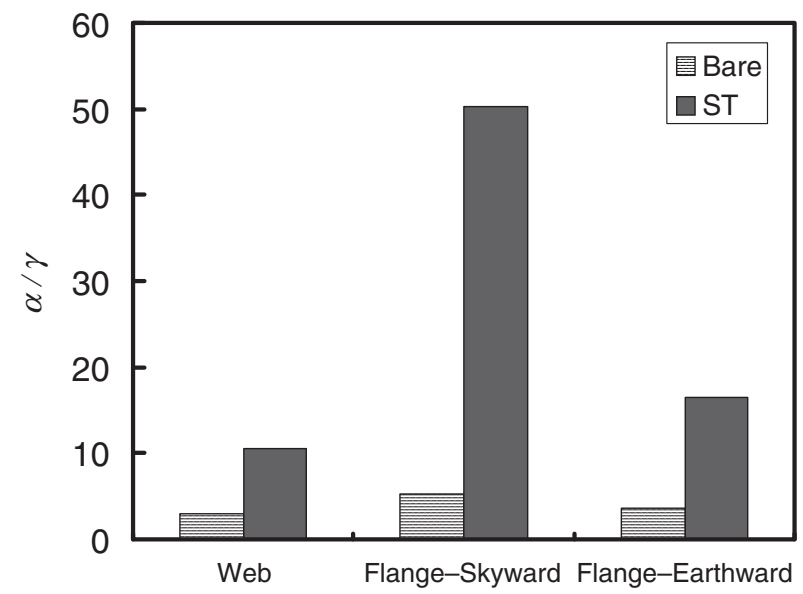

Fig. 5 Protective ability index (PAI), $\alpha / \gamma$ of the rust layer formed on the vertical member (web), the skyward surface of the lower horizontal flange (flange-skyward) and the earthward surface of the lower horizontal flange (flange-earthward) of the weathering steel bridge with (noted ST) and without (noted Bare) the surface treatment.

correlation between corrosion rate and the mass ratio $\left(\alpha / \gamma^{*}\right)$ of crystalline $\alpha-\mathrm{FeOOH}$ to the total mass of $\gamma$-FeOOH, $\beta$ $\mathrm{FeOOH}$ and spinel-type iron oxide formed under chloride containing atmosphere. Those mass ratio indices, the $\alpha / \gamma$ and $\alpha / \gamma^{*}$, have been registered as the protective ability index (PAI) for the weathering steel rust layer. ${ }^{11)}$ Quite recently, Ishikawa et ll $^{22)}$ have reported that the $\alpha / \gamma$ is effective to assess the rust stability and the corrosion of $\mathrm{Fe}-\mathrm{Ni}$ and $\mathrm{Fe}-\mathrm{Cr}$ binary alloys is suppressed at the $\alpha / \gamma>2$, which is in agreement with the case of weathering steels. ${ }^{2,9,11,23)}$

Figure 5 shows the $\alpha / \gamma$, the PAI in a low chloride environment, of the rust layer collected at the bare and coated portions of the web, the flange-skyward and the flangeearthward, where the mass fractions of $\alpha-\mathrm{FeOOH}, \beta-\mathrm{FeOOH}$, $\gamma$-FeOOH and $\mathrm{Fe}_{3} \mathrm{O}_{4}\left(M_{\alpha}, M_{\beta}, M_{\gamma}\right.$ and $M_{\mathrm{s}}$ respectively) were calculated using the diffraction intensity of each crystal phase $\left(I_{\alpha}, I_{\beta}, I_{\gamma}\right.$ and $I_{\mathrm{s}}$ respectively) through the following equation,

$$
\begin{aligned}
& M_{\mathrm{i}}=M_{\mathrm{iA}} \cdot\left(I_{\mathrm{i}} / I_{\mathrm{iA}}\right) / \sum\left(M_{\mathrm{jA}} \cdot I_{\mathrm{j}} / I_{\mathrm{jA}}\right) \\
& (\mathrm{i}, \mathrm{j}=\alpha, \beta, \gamma, \mathrm{S})
\end{aligned}
$$

where $M_{\mathrm{iA}}, M_{\mathrm{jA}}$ and $I_{\mathrm{iA}}, I_{\mathrm{jA}}$ are the mass fraction and the diffraction intensity of a bridge rust sample in the literature. ${ }^{24)}$ The diffraction intensities were obtained by integrating subdivided diffraction intensities in each $0.01^{\circ} 2 \theta$-step of diffraction peaks of $\alpha$ - $\mathrm{FeOOH} / 9.45^{\circ}-11.05^{\circ}$ (110), $\beta$ $\mathrm{FeOOH} / 5.17^{\circ}-6.37^{\circ}(110), \gamma-\mathrm{FeOOH} / 5.94^{\circ}-7.74^{\circ}(020)$ and $\mathrm{Fe}_{3} \mathrm{O}_{4} / 14.30^{\circ}-14.70^{\circ}$ (220), after removing the background of the XRD pattern using Sonneveld-Visser method. ${ }^{25)}$ Multiple measurements on the same samples indicated that the experimental scattering of $\alpha / \gamma$ value was within a few percent. The $\alpha / \gamma$ of the rust layer at the bare portion ranges between $3-5$. This value is comparable to typical value obtained for bare weathering steel coupons exposed underneath bridges for more than 10 years to a low chloride environment. ${ }^{26)}$

It is clear that the $\alpha / \gamma$ of the rust layer at the coated portion is much higher than that at the bare portion. This indicates that $\alpha$-FeOOH was predominantly formed under the effect of the surface treatment as has been argued previously.

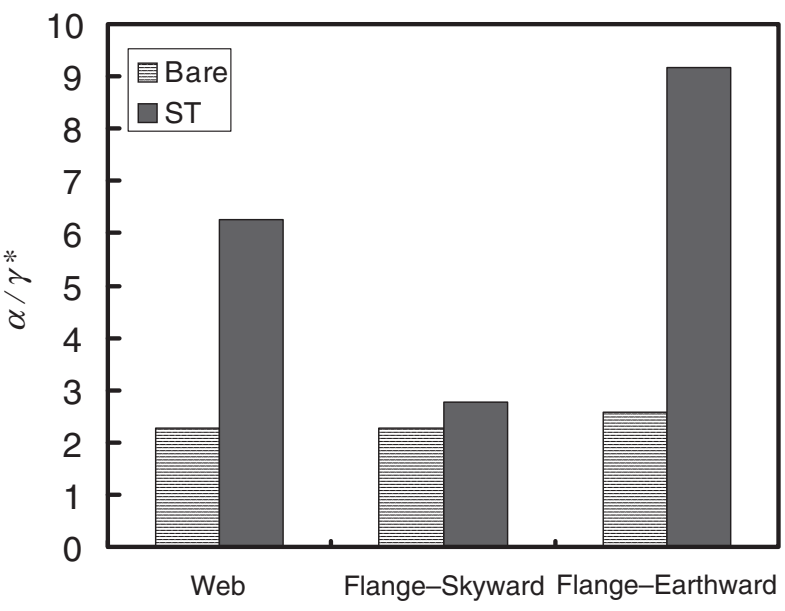

Fig. 6 Protective ability index (PAI), $\alpha / \gamma^{*}$ of the rust layer formed on the vertical member (web), the skyward surface of the lower horizontal flange (flange-skyward) and the earthward surface of the lower horizontal flange (flange-earthward) of the weathering steel bridge with (noted ST) and without (noted Bare) the surface treatment.

It is interesting to note that the $\alpha / \gamma$ of the rust layer collected at the coated portions of the flange-skyward showed extremely high value. As was discussed above, the pigments in the surface treatment film tended to accumulate in the upper side of the horizontal member. In the same way, it is considered that the effective $\mathrm{Cr}_{2}\left(\mathrm{SO}_{4}\right)_{3}$ in the surface treatment film promoting the protective rust formation ran off along the web plate and stayed on the surface of the flange-skyward for a long term. This stagnant accumulation of the effective compound on the steel surface results in the high value of the $\alpha / \gamma$.

Because the XRD patterns indicated the existence of a certain amount of airborne salt as discussed above, it is also worth considering the $\alpha / \gamma^{*}$ as the PAI in a higher chloride environment. The $\alpha / \gamma^{*}$, calculated by the eq. (1), of the rust layer collected at the bare and coated portions of the web, the flange-skyward and the flange-earthward are shown in Fig. 6. The $\alpha / \gamma^{*}$ behavior is in good agreement with the variation of the $\alpha / \gamma$ except for the coated portion of the flange-skyward. It was pointed out in the previous section that accumulation of salt particles on the outermost surface of the flangeskyward resulted in relatively high $\beta$-FeOOH intensity. This higher amount of $\beta$-FeOOH decreases the $\alpha / \gamma^{*}$ at the coated portion of the flange-skyward. Nevertheless, the $\alpha / \gamma^{*}$ was increased by the effect of the surface treatment.

In conclusion, it can be said that the surface treatment worked well to promote the formation of the protective goethite rust layer, which resulted in increase in the PAI, for the weathering steel bridge during the 10-year exposure.

\section{Conclusion}

We have examined the structure of rust layer formed on a weathering steel bridge, to which the surface treatment designed to promote the formation of the protective $\mathrm{Cr}$ goethite rust layer has been applied, using X-ray diffraction spectroscopy at SPring-8 synchrotron radiation facility. The concluding remarks obtained were as follows. 
(1) The formation of $\alpha-\mathrm{FeOOH}$ was encouraged and/or crystal growth of $\gamma$-FeOOH was suppressed by the surface treatment.

(2) The PAI, $\alpha / \gamma$ and $\alpha / \gamma^{*}$, was increased by the surface treatment. This indicates that the protective goethite was predominantly formed under the effect of the surface treatment.

(3) It can be pointed out that the surface treatment worked well to promote the formation of the protective goethite rust layer on the weathering steel bridge.

\section{Acknowledgment}

The authors would like to thank the Advanced Large-Scale Research Facilities Strategic Utilization Program promoted by MEXT for offering the opportunity to use the BL19B2 of SPring-8. The surface treatment promoting the protective rust layer formation has been jointly developed with SHINTO PAINT CO., LTD., and the authors wish to deeply express our gratitude to SHINTO PAINT CO., LTD.

\section{REFERENCES}

1) T. Misawa, K. Asami, K. Hashimoto and S. Shimodaira: Corros. Sci. 14 (1974) 279-289.

2) M. Yamashita, H. Miyuki, Y. Matsuda, H. Nagano and T. Misawa: Corros. Sci. 36 (1994) 283-299.

3) M. Yamashita and H. Uchida: Hyperfine Interactions 139/140 (2002) 153-166.

4) D. C. Cook, R. Balasubramanian, S. J. Oh and M. Yamashita: Hyperfine Interactions 122 (1999) 59-70.

5) M. Yamashita, T. Misawa, H. E. Townsend and D. C. Cook: J. Japan Inst. Metals 64 (2000) 77-78.

6) T. Kamimura, S. Nasu, T. Tazaki, K. Kuzushita and S. Morimoto: Mater. Trans. 43 (2002) 694-703.

7) M. Yamashita, H. Miyuki, H. Nagano and T. Misawa: Tetsu-to-Hagane
83 (1997) 448-453.

8) H. Miyuki, M. Yamashita, M. Fujiwara and T. Misawa: Zairyo-toKankyo 47 (1998) 186-192.

9) M. Yamashita, H. Miyuki and H. Nagano: The Sumitomo Search 57 (1995) 12-16.

10) H. Miyuki, T. Kamimura, T. Doi, M. Yamashita and T. Misawa: Materia Japan 41 (2002) 39-41.

11) T. Kamimura, S. Hara, H. Miyuki, M. Yamashita and H. Uchida: Corros. Sci. 48 (2006) 2799-2812.

12) The Powder Diffraction File, International Centre for Diffraction Data, Newtown Square, (1995).

13) R. M. Cornell and U. Schwertmann: The Iron Oxides, (VCH, Weinheim, 1996).

14) Y. Tamaura, P. V. Buduan and T. Katsura: J. C. S. Dalton, (1981) 1807-1811.

15) M. Yamashita, H. Konishi, T. Kozakura, J. Mizuki and H. Uchida: Mater. Trans. 46 (2005) 1004-1009.

16) M. Yamashita, H. Nagano, T. Misawa and H. E. Townsend: ISIJ International 38 (1998) 285-290.

17) M. Yamashita, H. Konishi, J. Mizuki and H. Uchida: Mater. Trans. 45 (2004) 1920-1924.

18) T. Kamimura, S. Nasu, T. Segi, T. Tazaki, H. Miyuki, S. Morimoto and T. Kudo: Corros. Sci. 47 (2005) 2531-2542.

19) M. Yamashita, H. Miyuki and H. Nagano: Curr. Adv. Mater. Processes 10 (1997) 556.

20) M. Yamashita and T. Misawa: Corrosion Engineering 49 (2000) 96-98.

21) K. Shiotani, T. Nakayama, H. Kihira, H. Miyuki, M. Takemura, F. Kawabata, K. Abe, T. Kusunoki, Y. Watanabe and K. Matsui: [SABI [rust] Chemistry on the phase-III toward Realizing Minimum Maintenance Bridge Conception.] Proceedings of JSCE 132nd Symposium, (2001) 73-82.

22) T. Ishikawa, A. Maeda, K. Kandori and A. Tahara: Corrosion 62 (2006) 559-567.

23) K. Asami: Characterization of Corrosion Products on Steel Surface, (eds. Y. Waseda and S. Suzuki, Springer, 2006) pp. 159-197.

24) S. Hara, M. Yamashita, T. Kamimura and M. Sato: J. Japan Inst. Metals, (2007) in press.

25) E. J. Sonneveld and J. W. Visser: J. Appl. Cryst. 8 (1975) 1-8.

26) M. Yamashita, K. Asami, T. Ishikawa, T. Ohtsuka, H. Tamura and T. Misawa: Zairyo-to-Kankyo 50 (2001) 521-530. 